\title{
The effectiveness of concomitant intravaginal laser treatment in patients undergoing mesh excision due to vaginal exposure or extrusion
}

\author{
๑Kubilay Sarıkaya, ®Çağrı Şenocak, @Muhammed Arif İbiş, @Fahri Erkan Sadioğlu, @Mehmet Çiftçi, \\ (1) Ömer Faruk Bozkurt \\ Keçiören Training and Research Hospital, Department of Urology, Ankara, Turkey
}

Cite this article as: Sarıkaya K, Şenocak Ç, İbiş MA, Sadioğlu FE, Çiftçi M, Bozkurt ÖF. The effectiveness of concomitant intravaginal laser treatment in patients undergoing mesh excision due to vaginal exposure or extrusion. Anatolian Curr Med J 2022; 4(1); 64-69.

\begin{abstract}
Objective: To investigate the efficacy of intravaginal laser therapy applied concurrently with mesh excision for the treatment of vaginal polypropylene mesh exposure or extrusion, which is the most common complication after transobturator tape (TOT), on the recurrence of incontinence.

Material and Method: The data of 49 patients who underwent mesh excision due to vaginal mesh exposure or extrusion in our clinic between January 2009 and January 2020 were retrospectively analyzed. The patients were divided into two groups as simultaneous intravaginal laser therapy during the mesh excision (EL, $n=23)$ and only mesh excision $(E O, n=26)$. Data of the patients and long-term stress urinary incontinence (SUI) recurrence rates were determined and the groups were compared.

Results: The mean age of the patients was $50.4 \pm 9.9$ years and the mean follow-up period was $33.3 \pm 22.1$ months. SUI recurrence in 1-h pad test was significantly lower in the EL group than the EO group at the 12 th month evaluation $(8.7 \%$ vs $34.6 \% \mathrm{p}=0.030$ respectively). According to multivariate regression analysis operation type was an independent risk factor for SUI recurrence $(\mathrm{p}=0.021)$. However, there was no significant difference between the groups in terms of postoperative incontinence quality of life questionnaire (I-QOL) scores $(\mathrm{p}=0.082)$.

Conclusion: Concomitant laser treatment applied with the mesh excision for the treatment of vaginal meshexposure or extrusion secondary to TOT surgery provides a significant advantage in preventing the recurrence of SUI.
\end{abstract}

Keywords: Laser therapy, mesh erosion, incontinence recurrence

\section{INTRODUCTION}

Stress urinary incontinence (SUI) is involuntary incontinence caused by increased intra-abdominal pressure such as coughing, laughing, and weight lifting that affects approximately $45-50 \%$ of women (1). Surgical treatment methods of SUI include bulking agents, open or laparoscopic pubovaginal sling or Burch colposuspension or mid-urethral sling procedures (2). Mid-urethral sling procedures and minimally invasive methods have become the first choice in the surgical treatment of SUI due to their many advantages such as easy application, cost effective, short learning curve, short operation time and high success rates (3).Despite the many advantages that mid-urethral sling procedures provide, polypropylene mesh (PPM) exposure or extrusion, which is reported to be approximately 3.8-15 $\%$, is the most common complication of these surgeries
(4). It has been reported that within 5 years after mid-urethral sling surgeries, $3.7 \%$ require additional treatment due to recurrent SUI secondary to mesh excision (5). It has been reported that after partial or total mesh removal performed due to vaginal extrusion, up to $40 \%$ of SUI recurs in patients and therefore second anti-incontinence surgery or concomitant surgery is required (6). Recently, more minimally invasive and easily applicable laser therapy methods have been used in the treatment of SUI in order to reduce the complications of sling materials, and success rates comparable to midurethral sling procedures have been reported $(7,8)$. Although laser applications are used as the primary treatment method in SUI, there is not enough data in the literature regarding the efficacy of laser treatments applied simultaneously with the mesh removal operation 
performed due to vaginal PPM exposure or extrusionto prevent recurrence of incontinence. Therefore, in this study, we aimed to evaluate the efficacy of erbium-doped yttrium aluminum garnet (Er: YAG) laser therapy, which we applied concomitantly, in preventing SUI recurrence in patients underwent PPM excision due to vaginal mesh exposure or extrusion.

\section{MATERIAL AND METHOD}

After obtaining approval from the ethics committee of Health Sciences University Keçiören Training and Research Hospital (Date: 22.06.2021, No:2012KAEK-15/2335), the data of 56 patients who underwent mesh excision due to vaginal PPM exposure or extrusion secondary to transobturator tape (TOT) surgery in our clinic between January 2009 and January 2020 were retrospectively analyzed. All of the study process was carried out accordance with the ethical rules and the principles of the Declaration of Helsinki. Data of 49 of these patients with a median 1.4 (0.52.6) $\mathrm{cm}$ mesh exposure or extrusion were available for the study.Seven of the patients who developed mesh extrusion were excluded due to missing data. The patients were divided into two groups as those who received concomitant Er: YAG laser treatment (excision + laser=EL) and those who underwent excision only (EO). All the patients with vaginal mesh exposure or extrusion were informed about possible SUI incontinence recurrence after mesh excision and positive efficacy and possible side effects of laser treatment methods and informed consent forms were obtained. After an informed discussion, decisions for EL or EO procedures were made according to patient's preferences and the physician's recommendations. Patients who received medical treatment after mesh excision due to urge urinary incontinence, over active bladder or with urge-predominant mixed urinary incontinence were excluded. Other exclusion criteria were the presence of severe obesity with a body mass index> 35 during excision, cystocele requiring additional surgery, rectocele, pelvic organ prolapse, previous additional vaginal-gynecological operation, or a history of irradiation. In both groups, all patients received intravaginal estradiol therapy for at least 6 months prior to mesh excision in the preoperative period. Urine analysis and urine culture, preoperative urodynamics (UD), stress and Q-tip test with vaginal examination, and cystoscopy were routinely performed for all patients before mesh excision surgery. Cystocele gradings were classified according to the SWIFT classification (9). One-hour pad test was used to determine the presence of incontinence before and 12 months after the operation. Postoperative 1-h pad test results were taken as a basis for determining SUI recurrence. In 1 - $h$ pad test, an increase in pad weight of more than $2 \mathrm{~g}$ in one hour was considered as SUI presence (10). To determine quality of life in the postoperative period, we used the Incontinence Quality of Life Questionnaire (I-QOL) form, which is validated for Turkish (11). In the EO group, after 16$18 \mathrm{fr}$ urethral catheterization in lithotomy position under spinal anesthesia, the vaginal erosive mesh area of the patients was identified and marked, and eroded piece of the mesh was separated from the vaginal mucosa with sharp-blunt dissections and removed partially. At this stage, care was taken to protect the vaginal mucosa outside the eroded area and no additional mucosal dissection was performed. The part of the mesh entering both obturator foramen was not removed. Following the procedure, vaginal mucosa was closed with 2/3-zero absorbable suture $\left(\right.$ Vicryl $^{\circledR}$ ) and the procedure was completed. In the EL group, mesh excision was performed similarly to the EO group; then, a single session non-ablative $2940 \mathrm{~nm}\left(10 \mathrm{~J} / \mathrm{cm}^{2}\right.$ fluence and $7 \mathrm{~mm}$ spot size) Er: YAG laser (Asclepion Juliet Er:YAG Lazer,Med-Laser,Turkey) treatment was applied to the anterior vaginal wall following suture closure of the surgical incision line.At this stage, care was taken not to apply laser energy directly above the suture line. Laser energy was applied to the vaginal mucosa and the suburethral area around the suture line.Laser treatment was performed in three phases. In the first phase, full circumference of the vaginal canal was irradiated applying two passes around 650J of laser energy. In the second phase, a 900 angular adapter was used and the anterior vaginal wall was irradiated with a fractionated smooth beam using several longitudinal passes with total 250J of energy. Then, following the second phase, vestibular mucosa and introitus were irradiated directly with fractionated smooth beam in three passes with a 100J of energy.

In the postoperative period, no additional treatment like vaginal estradiol was given to the patients. Patients in both groups were invited for a follow-up at the 12th month and evaluated with 1 -h pad-test to determine SUI presence. Patients who did not have SUI in the 1-h pad test before mesh excision and who were found to have SUI in the 1-h pad test at the 12th month after excision were considered to have recurrence of SUI. After the 12th month, the patients were called for a follow-up once a year for 5 years.

\section{Statistical Analysis}

All statistical analyses were performed using the SPSS 24.0 (IBM Corp., Chicago) software for Windows. Descriptive statistics are given as "frequency" and "description." For data with normal distribution, 
independent samples- $t$ test was used as means and standard deviation. In the univariate analysis, ChiSquare Test was used for nominal data, while the MannWhitney $U$ test was used for nonparametric variables. A p-value of $<0.05$ was considered statistically significant. Univariate regression analysis was performed to predict SUI recurrence. Multivariate regression analysis was performed by creating a model with values of $\mathrm{p}<0.1$ in univariate analysis.

\section{RESULTS}

The mean age of the patients was $50.4 \pm 9.9$ years and the mean follow-up period was $33.3 \pm 22.1$ months. 23 (46.9\%) of the patients were in the EL group and 26 (53.1\%) were

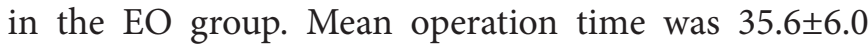
minutes and mean hospital stay was $1.1 \pm 0.3$ days. 17 of the patients $(34.6 \%)$ had SUI in the 1 -h pad test in postoperative 12th month. The general characteristics of the patients are shown in Table 1. The mean age was $51.2 \pm 10.7$ years in the EL group and $49.8 \pm 9.3$ years in EO group $(p=0.634)$. The mean follow-up period was

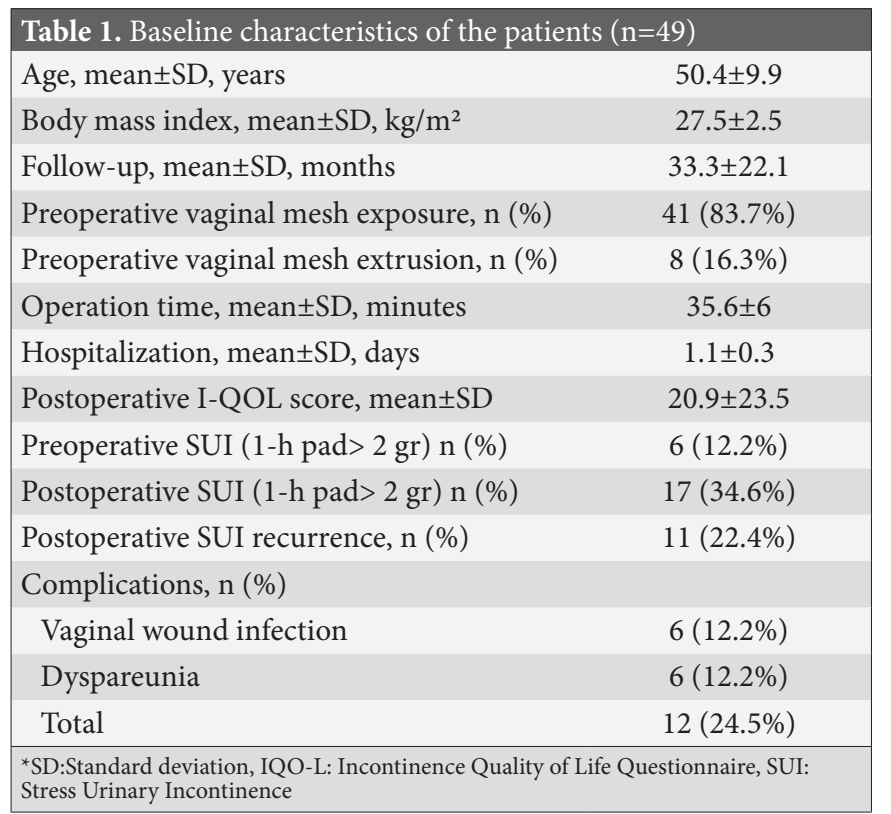

Table 3. Univarite regression analyses for predicting SUI recurrence

\begin{tabular}{|lccc|}
\hline & $\mathbf{R}+(\mathbf{n}=\mathbf{1 6})$ & $\mathbf{R}-(\mathbf{n}=\mathbf{3 3})$ & $\mathbf{p}$ \\
\hline $\begin{array}{l}\text { Age, mean } \pm \text { SD, years } \\
\text { Body mass index, } \\
\text { mean } \pm S D\end{array}$ & $48.87 \pm 10.1$ & $51.27 \pm 10.1$ & 0.434 \\
$\begin{array}{l}\text { Operation time, } \\
\text { mean } \pm S D, \text { minutes }\end{array}$ & $33.75 \pm 5.6$ & $36.51 \pm 6.1$ & 0.132 \\
$\begin{array}{l}\text { Preoperative pad / day, } \\
\text { mean } \pm S D(n)\end{array}$ & $0.75 \pm 0.9$ & $0.60 \pm 0.8$ & 0.535 \\
$\begin{array}{l}\text { Excised mesh length, } \\
\text { mean } \pm S D, \text { cm }\end{array}$ & $1.90 \pm 0.6$ & $1.60 \pm 0.5$ & 0.079 \\
\begin{tabular}{l} 
Operation type, $\mathrm{n}(\%)$ \\
\hline $\begin{array}{l}\text { SuI: Stress urinary incontinence, R+: Recurrence +, R-: Recurrence -, SD: Standard } \\
\text { deviation }\end{array}$
\end{tabular} & $23(47)$ & $26(53)$ & $0.032^{*}$ \\
\hline
\end{tabular}

$27.7 \pm 17.8$ months in the EL group and $38.3 \pm 24.6$ months in EO group $(\mathrm{p}=0.097)$. However, the mean operation time was $37.3 \pm 5.8$ minutes in the EL group and $34.0 \pm 5.8$ minutes in the EO group $(p=0.049)$. There was no significant difference between the EL and EO groups in terms of excised mesh length $(1.73 \pm 0.6 \mathrm{~cm}$ vs $1.68 \pm 0.5$ $\mathrm{cm}, \mathrm{p}=0.723)$. According to the postoperative 1 -h pad test, $2(8.7 \%)$ of the patients in the EL group and 9 (34.6) in the EO group had SUI recurrence $(\mathrm{p}=0.030)$. However, there was no significant difference between the groups in terms of I-QOL scores at the 12th month $(\mathrm{p}=0.082)$ (Table 2).

A univariate analysis was performed to predict the factors on SUI recurrence. The parameters for univariate regression analysis were age, BMI, operation time, preoperative pad/day, excised mesh length, and operation type (Table 3 ). Then, a multivariate regression analysis was performed to predict SUI recurrence using operation type (EL or EO), excised mesh length, and BMI variables. According to this model, operation type was an independent risk factor for SUI recurrence $(\mathrm{p}=0.021)$ (Table 4).

\begin{tabular}{|c|c|c|c|}
\hline & EL $(n=23)$ & EO $(n=26)$ & p \\
\hline Age, mean $\pm S D$, years & $51.2 \pm 10.7$ & $49.8 \pm 9.3$ & 0.634 \\
\hline Body mass index, mean \pm SD & $27.5 \pm 2.7$ & $27.4 \pm 2.3$ & 0.887 \\
\hline Follow-up, mean $\pm S D$, months & $27.7 \pm 17.8$ & $38.3 \pm 24.4$ & 0.097 \\
\hline $\begin{array}{l}\text { Operation time, mean } \pm S D \text {, } \\
\text { minutes }\end{array}$ & $37.3 \pm 5.8$ & $34.0 \pm 5.8$ & $0.049^{*}$ \\
\hline $\begin{array}{l}\text { Hospitalization, mean } \pm S D \text {, } \\
\text { days }\end{array}$ & $1.2 \pm 0.5$ & $1.1 \pm 0.4$ & 0.460 \\
\hline $\begin{array}{l}\text { Excised mesh length, } \\
\text { mean } \pm \mathrm{SD}, \mathrm{cm}\end{array}$ & $1.73 \pm 0.6$ & $1.68 \pm 0.5$ & 0.723 \\
\hline $\begin{array}{l}\text { Postoperative I-QOL score, } \\
\text { mean } \pm \text { SD }\end{array}$ & $13.2 \pm 16.9$ & $27.8 \pm 26.6$ & 0.082 \\
\hline $\begin{array}{l}\text { Preoperative SUI }(1-\mathrm{h} \text { pad }>2 \mathrm{~g}) \\
\mathrm{n}(\%)\end{array}$ & $2(8.7 \%)$ & $4(15.4 \%)$ & 0.476 \\
\hline $\begin{array}{l}\text { Postoperative SUI (1-h pad }>2 \\
\text { g) n (\%) }\end{array}$ & $4(17.4 \%)$ & $13(50.0 \%)$ & $0.041^{*}$ \\
\hline $\begin{array}{l}\text { Postoperative SUI recurrence, } \\
\mathrm{n}(\%)\end{array}$ & $2(8.7 \%)$ & $9(34.6 \%)$ & $0.032^{*}$ \\
\hline Complication, $\mathrm{n}(\%)$ & $4(17.4 \%)$ & $8(30.8 \%)$ & 0.115 \\
\hline Vaginal wound infection & $3(13.0 \%)$ & $3(11.5 \%)$ & 0.873 \\
\hline Dyspareunia & $1(3.8 \%)$ & $5(21.7 \%)$ & 0.057 \\
\hline
\end{tabular}

${ }^{\star}$ SD:Standard deviation, IQO-L: Incontinence Quality of Life Questionnaire, SUI Stress Urinary Incontinence

Table 4. Multivariate regression analysis results for predicting SUI recurrence

\begin{tabular}{|c|c|c|c|c|c|}
\hline \multirow{2}{*}{ Variables } & \multicolumn{2}{|c|}{$\begin{array}{l}\text { Regression } \\
\text { coefficients }\end{array}$} & \multicolumn{2}{|c|}{ 95\% CI } & \multirow[b]{2}{*}{ p } \\
\hline & B & SE & $\begin{array}{l}\text { Lower } \\
\text { Limit }\end{array}$ & $\begin{array}{l}\text { Upper } \\
\text { Limit }\end{array}$ & \\
\hline Constant & 8.22 & 4.04 & & & 0.042 \\
\hline Operation type & 1.8 & 0.78 & 0.04 & 0.77 & $0.021^{*}$ \\
\hline Excised mesh length & 1.18 & 0.68 & 0.848 & 12.36 & 0.086 \\
\hline BMI & 0.22 & 0.41 & 0.95 & 1.64 & 0.117 \\
\hline
\end{tabular}

CI:Confidence intervals, B: Unstandardized beta, SE:Standard error, and BMI: Bodymassindex. 


\section{DISCUSSION}

Mid-urethral sling operations have been considered as the first choice in the surgical treatment of SUI due to the high success rates reported, the ease of application, and other advantages it provides (12). Although autologous transobturator rectus fascia is used in limitedly selected patients with a history of hypersensitivity to polypropylene and similar materials, currently PPM is the most preferred sling material in mid-urethral sling operations due to its ease of application and no need for additional surgical operation (13). Despite their advantages, the most common complication of PPM suspension materials is vaginal mesh exposure and extrusion and intraurethral or intravesical erosion (14). Studies have reported that re-operation is required for PPM erosion at a rate of approximately $2-12 \%$ after either retropubic sling, TOT or mini-sling surgeries in the long-term (15). The treatment of mesh exposure secondary to mid-urethral sling operations is partial or total removal of the mesh (16). However, various studies have reported that SUI recurs in approximately $30-60 \%$ of patients following the removal of the mesh (17). Jonathan et al. (18) reported the results of 102 patients who underwent revision due to mesh erosion. Accordingly, sling division was performed in 45 patients, mesh excision in 57, and SUI recurrence was observed at a rate of $13 \%$ in the division group and $56 \%$ in the excision group. Similar to the literature data, in our study, there was no significant difference between the groups in terms of SUI rates in 1-h pad test in the preoperative period, but the SUI recurrence was significantly higher in the EO group than in the EL group. These results support the idea that SUI recurrence is seen at a high rate following mesh excision and that additional surgery is required in these patients due to SUI. Although there is no definite recommendation in the literature, pubovaginal sling and open colposuspension surgeries are some secondary surgical treatment options of SUI developing after mid-urethral sling surgeries (19). Laparoscopic approaches and more minimally invasive methods in which the erosive mesh is removed locally are also shown as alternative surgical treatment options (20). Studies have shown that type1 and type- 3 collagen levels in the pubocervical fascia are significantly lower in patients with SUI and collagen reserves are further reduced as a result of decreased hormonal support with menopause, which triggers SUI by weakening the formations that support the vaginal hammock structure (21). The photothermal laser energy supports the collagen tissue in this area and strengthens the vaginal hammock structure and pelvic floor (22). As a result of these findings, laser therapy procedures have been used frequently as a minimally invasive treatment option and successful results have been reported at a level comparable to mid-urethral sling operations $(7,8)$. Nobou (23) compared the results of TVT, TOT, and laser treatment in 50 patients and stated that the 1-h pad test and International Consultation of Incontinence Questionnaire Short Form (ICIQ-SF) score results showed considerable improvement in all three groups and were comparable to each other ( $\mathrm{p}$. $<0.001$ and $\mathrm{p}<0.001$, respectively). In another recent study including a total of 114 postmenopausal women, Mija et al. (24) compared patients who received Er: YAG laser treatment and patients in the "sham" group who received no treatment in terms of SUI, quality of life, and improvement in sexual functions. The improvement in ICIQ-SF, pelvic organ prolapse, urinary incontinence, sexual questionnaire short form (PISQ-12), and the female sexual function index (FSFI) scores was significantly higher than the "sham" group, with no serious side effects observed in any patient ( $\mathrm{p}<0.001, \mathrm{p}=0.014$ and $\mathrm{p}=0.025$ respectively). In another similar study, Andrzej et al. (25) reported the results of 59 patients applied Er: YAG laser treatment. The authors reported that intravaginal laser therapy provided significant improvement in patients with mild and moderate SUI, but did not provide sufficient improvement in patients with severe SUI. In another similar study, Erel et al. (26) reported the results of 82 patients treated with Er: YAG laser therapy for SUI. They found a significant improvement in ICIQ-SF and King's Health Questionnaire (KHQ-UI) scores after laser treatment $(\mathrm{p}<0.0001$ and $\mathrm{p}<0.0001$, respectively). In another study, Ogrinc et al. (27) reported the results of 175 patients (66\% with SUI and $34 \%$ with mixed urinary incontinence) who received Er: YAG laser treatment. According to their findings, a $77 \%$ improvement rate was observed in patients with SUI after intravaginal laser treatment, while there was a $34 \%$ improvement in patients with mixed urinary incontinence (MUI). Besides, there were no serious side effects other than minimal discomfort and pain during laser application. Similar to the literature, in our study, the SUI recurrence in the 1-h pad test was found to be significantly lower in the EL group compared to the EO group, but there was no significant difference between the groups in terms of I-QOL scores. Similar to the results reported in the primary treatment of patients with SUI or stress predominant MUI, we also observed that Er: YAG laser treatment contributed significantly to the reduction of SUI recurrence in patients with SUI whounderwent mesh excision. The type of operation (EL or EO) performed was the only independent risk factor for SUI recurrence in the multivariate analysis, which also supports this finding. Moreover, we observed that concomitant laser treatment during mesh excision developing secondary to PPM exposure or extrusion did not cause serious 
adverse effects, similar to the literature data, and the rates of complications were similar between the EL and EO groups. In our study, we determined no significant difference between the laser group and the excision group in terms of wound infection in the vaginal area where the mesh was excised in the postoperative period. The mean excised mesh length was similar between the groups, suggesting that the length of the excised part of the mesh had no effect on SUI recurrence. The mesh sections removed from our patients were not very long, which may have affected this finding. This points out that intravaginal laser treatment with concomitant applied during mesh excision can be performed safely as in primary SUI treatment, significantly reducing the need for additional surgery due to recurrent SUI. On the other hand, although there was no significant difference between the groups in our study, dyspareunia was less in the EL group in the postoperative period. The lack of a statistical difference between the groups in terms of dyspareunia may be related to the small number of patients in our study. In studies with larger samples, the rate of dyspareunia is likely to be significantly lower in the laser group, which is consistent with the idea that intravaginal laser therapy contributes positively to sexual functions. Although there are many recent studies reporting positive results for the effectiveness of laser treatment in the primary treatment of SUI, there is not enough data on preventing SUI recurrence with laser therapy in patients who underwent mesh excision. We think more prospective and randomized studies with larger samples are needed in this area. Therefore, we believe that our study will make a significant contribution to the literature.

The most important limitation of our study is absence of randomization due to its retrospective nature. Another limitation is that SUI severity could not be differentiated as mild, moderate or severe in a 1-h pad test before excision or laser operations. In addition, the absence of long-term incontinence recurrence rates of the groups due tothe short follow-up time can be considered as another important limitation.

\section{CONCLUSION}

Intravaginal laser treatment can be applied effectively and safely simultaneously with the vaginal mesh excision that develops secondary to TOT surgery,as in primary SUI patients. Laser treatments contribute significantly to the reduction of SUI recurrence in patients undergoing mesh excision, and significantly reduces the need for additional anti-incontinent surgical intervention for the treatment of SUI recurrence.

\section{ETHICAL DECLARATION}

Ethics Committee Approval: Ethical approval was obtained from the ethics committee of Health Sciences University Keçiören Training and Research Hospital (Date: 22.06.2021, Decision No:2012-KAEK-15/2335).

Informed Consent: Because the study was designed retrospectively, no written informed consent form was obtained from patients.

Referee Evaluation Process: Externally peer-reviewed.

Conflict of Interest Statement: The authors have no conflicts of interest to declare.

Financial Disclosure: The authors declared that this study has received no financial support.

Author Contributions: All of the authors declare that they have all participated in the design, execution, and analysis of the paper, and that they have approved the final version.

\section{REFERENCES}

1. Takahashi S, Takei M, Nishizawa O, et al. Clinical guidelines for female lower urinary tract symptoms. Tokyo: The Neurogenic Bladder Society; 2013: 6-168.

2. Jarvis GJ. Surgery for genuine stress incontinence. Br J Obstet Gynaecol 1994; 101: 371-4.

3. Henriksson L, Ulmsten U. A urodynamic evaluation of the effects of abdominal urethrocystopexy and vaginal sling urethroplasty in women with stress incontinence. Am J Obstet Gynecol 1978; 131: 77-82.

4. Keršič M, Keršič M, Kunič T, et al. Single-incision mini-sling for the treatment of female stress urinary incontinence: is it actually inferior to transobturator vaginal tape and tension-free vaginal tape? Gynecol Minim Invasive Ther 2020; 9: 123-30.

5. Kenton K, Stoddard AM, Zyczynski H, et al. 5-year longitudinal follow-up after retropubic and transobturator midurethral slings the urinary incontinence treatment network. J Urol 2015; 193: 203-10.

6. Ramart P, Ackerman AL, Cohen SA, Kim JH, Raz S. The risk of recurrent urinary incontinence requiring surgery after suburethral sling removal for mesh complications. Urology 2017; 106: 203-9.

7. Fistonić N.Fistonić I.Guštek Š.F et al.Minimally invasive, nonablative Er:YAG laser treatment of stress urinary incontinence in women-a pilot study.Lasers Med Sci 2016; 31: 635-43.

8. Pardo J, Sola VR, Morale AA. Treatment of female stress urinary incontinence with Erbium-YAG laser in non-ablative mode. Eur J Obstet Gynecol Reprod Biol 2016; 204: 1-4.

9. Swift S. Current opinion on the classification and definition of genital tract prolapse. Curr Opin Obstet Gynecol 2002; 14: 503-7.

10. Orgensen L, Lose G, Anders J. One-hour pad weighing test for objective assessment of female incontinence. Obstet Gynecol 1987; 69: 39-43.

11. Eyigor S, Karapolat H, Akkoc Y, Yesil H, Ekmekci O. Quality of life in patients with multiple sclerosis and urinary disorders: reliability and validity of Turkish-language version of Incontinence Quality of Life Scale. J Rehabil Res Dev 2010; 47: 67-71.

12. Burkhard FC, Bosch JLHR, Cruz F et al. EAU Guidelines. Edn. presented at the EAU Annual Congress Copenhagen 2018. ISBN 978-94-92671-01-1. 2018. 
13. Niknejad K, Plzak LS, $3^{\text {rd }}$, Staskin DR, Loughlin KR. Autologous and synthetic urethral slings for female incontinence. Urol Clin North Am 2002; 29: 597-611.

14. Gomes CM, Carvalho FL, Bellucci CHS, et al. Update on complications of synthetic suburethral slings. Int Braz J Urol. 2017; 43: 822-34.

15. Berger AA, Tan-Kim J, Menefee SA. Long-term risk of reoperation after synthetic mesh midurethral sling surgery for stress urinary incontinence. Obstet Gynecol 2019; 134: 1047-55.

16. Welk B, Al-Hothi $\mathrm{H}$, Winick-Ng J. Removal or revision of vaginal mesh used for the treatment of stress urinary incontinence. JAMA Surg 2015; 150: 1167-75.

17. Ismail S, Chartier-Kastler E, Reus C, Cohen J, Seisen T, Phé $\mathrm{V}$. Functional outcomes of synthetic tape and mesh revision surgeries: a monocentric experience. Int Urogynecol J 2019; 30: 805-13.

18. Shaw J, Wohlrab K, Rardin C. Recurrence of stress urinary incontinence after midurethral sling revision: a retrospective cohort study. Female Pelvic Med Reconstr Surg 2017; 23: 184-7.

19. Bakali E, Johnson E, Buckley BS, Hilton P, Walker B, Tincello DG. Interventions for treating recurrent stress urinary incontinence after failed minimally invasive synthetic midurethral tape surgery in women. Cochrane Database Syst Rev 2019; 4: 9.

20. Yoshizawa T, Yamaguchi K, Obinata D, et al. Laparoscopic transvesical removal of erosive mesh after transobturator tape procedure. Int J Urol 2011; 18: 861-3.

21. Han L, Wang L, Wang Q, Li H, Zang H. Association between pelvic organ prolapse and stress urinary incontinence with collagen. Exp Ther Med 2014; 7: 1337-41.

22. El-Domyati M, Abd-El-Raheem T, Medhat W, Abdel-Wahab $\mathrm{H}$, Anwer MA. Multiple fractional erbium: yttrium-aluminumgarnet laser sessions for upper facial rejuvenation: clinical and histological implications and expectations. J Cosmet Dermatol 2014; 13: 30-7.

23. Okui N. Comparison between erbium-doped yttrium aluminum garnet laser therapy and sling procedures in the treatment of stress and mixed urinary incontinence. World J Urol 2019; 37: 885-9.

24. Blaganje M, Šćepanović D, Žgur L, Verdenik I, Pajk F, Lukanović A. Non-ablative Er:YAG laser therapy effect on stress urinary incontinence related to quality of life and sexual function: A randomized controlled trial. Eur J Obstet Gynecol Reprod Biol 2018; 224: 153-8

25. Kuszka A, Gamper M, Walser C, Kociszewski J, Viereck V. Erbium:YAG laser treatment of female stress urinary incontinence: midterm data. Int Urogynecol J 2020; 31: 1859-66.

26. Erel CT, Inan D, Mut A. Predictive factors for the efficacy of Er:YAG laser treatment of urinary incontinence. Maturitas 2020; 132: 1-6.

27. Ogrinc UB, Senčar S, Lenasi H. Novel, minimally invasive laser treatment of urinary incontinence in women. Lasers Surg Med 2015; 47: 689-97. 